\title{
Iodised salt availability in the United Kingdom
}

\author{
S. Bath, S. Button and M. P. Rayman \\ University of Surrey, Guildford, Surrey GU2 7XH, UK
}

Iodine deficiency has been demonstrated in the UK, particularly in pregnant women ${ }^{(1)}$. WHO recommend iodised salt for correcting iodine deficiency in a population and to ensure an adequate iodine intake ${ }^{(2)}$. Europe has a lower usage of iodised salt than other regions worldwide $^{(2)}$. A study in Cardiff showed that only two of the thirty-six salt samples had iodine concentrations suitable for the prevention of deficiency ${ }^{(1)}$. The current study aimed to assess iodised salt availability in supermarkets in a number of areas in the UK.

During June, July and August 2009, iodised salt availability was surveyed in five supermarket chains in each of the fourteen areas (largely identified as counties) of Southern England, in Wales (Cardiff) and two supermarket chains in Northern Ireland (Co Antrim). The cost of iodised salt was compared with that of standard table salt. Weighted iodised salt availability per supermarket chain was calculated by multiplying the market share ${ }^{(3)}$ by the percentage availability in each chain and a total weighted availability figure was calculated by summing the figures for all the five chains.

Iodised salt was available in thirty-two of the seventy-seven supermarkets (41.6\%); when taking market share into account, weighted availability was lower at $19.2 \%$. Cerebos (Premier Foods Group Ltd.) was the only iodised salt brand on sale and has a $0.6 \%$ volume share $^{(4)}$ of the table salt market. Iodised salt costs between 123 and 148 pence $/ \mathrm{kg}$ and standard table salt cost 23 pence $/ \mathrm{kg}$.

\begin{tabular}{lccc}
\hline $\begin{array}{l}\text { Supermarket } \\
\text { chain }\end{array}$ & $\begin{array}{c}\text { Market } \\
\text { share }(\%)^{(3)}\end{array}$ & $\begin{array}{c}\text { Percentage of stores } \\
\text { selling iodised salt }(\%)\end{array}$ & $\begin{array}{c}\text { Weighted } \\
\text { availability }(\%)\end{array}$ \\
\hline A & 31.0 & 0 & 0 \\
B & 17.2 & 0 & 0 \\
C & 15.9 & 37.5 & 5.96 \\
D & 11.4 & 86.7 & 9.88 \\
E & 3.9 & 86.7 & 3.38 \\
Total & 79.4 & 41.6 & 19.2 \\
\hline
\end{tabular}

After accounting for market share, fewer than $20 \%$ of supermarket shoppers will be exposed to iodised salt. Where iodised salt was available, it was up to six times more expensive and the premium price may dissuade consumers from purchasing iodised salt. Cerebos iodised salt has a low-volume share of the table salt market, reflecting poor availability.

Historic reports of goitre in the UK-prompted recommendations in the 1940s by the Medical Research Council that salt should be iodised $^{(5,6)}$. However, this recommendation was not followed and it was the adventitious increase in the iodine content of milk that led to the eradication of goitre in the $\mathrm{UK}^{(6)}$. It is therefore not surprising that iodised salt has a low profile.

Current availability of iodised salt is low in the UK and is unlikely to be contributing to the iodine status of the population. UK iodine intakes are dependent entirely on food choice and good sources, such as dairy products and fish, may not be consumed sufficiently by all. In view of the importance of iodine for neurological development during pregnancy and infancy ${ }^{(2)}$, the iodine status of the UK should be routinely monitored.

S. Bath gratefully acknowledges $\mathrm{PhD}$ studentship funding by the Waterloo Foundation and Wassen International.

1. Lazarus JH \& Smyth PP (2008) Lancet 372, 888

2. WHO \& UNICEF (2007) Geneva: WHO.

3. TNS Worldpanel (2009) www.tnsglobal.com/news/news DC7200A363C742BE922640832CE142FA.aspx

4. Symphony IRI (2010) $52 \mathrm{w} / \mathrm{e} 4$ September 10.

5. Kelly F \& Snedden W (1960) Geneva: WHO.

6. Phillips DI (1997) J Epidemiol Community Health 51, 391-393. 